\title{
The Durability Research of Thermal Insulation Glazed Hollow Bead Concrete under the Sulfate Attack
}

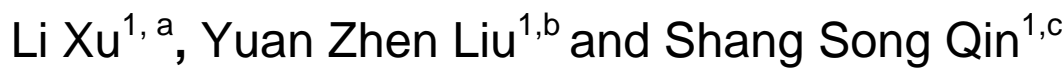 \\ ${ }^{1}$ Taiyuan University of Technology, 79 Yingze West Main Street, Taiyuan, Shanxi Province, China \\ a523623642@qq.com, bliuyuanzhen820@126.com, 'c qinshangsong@126.com
}

Keywords: glazed hollow bead, bed, thermal insulation concrete, building energy efficiency, sulfate attack, durability

\begin{abstract}
Thermal insulation glazed hollow bead concrete is a new type of insulating and beading building material, which is produced in the background of building energy efficiency, has been systematically researched in order to make it with a good workability under the sulfate attack. Theoretical analysis and experimental study have been made from water cement ratio, the glazed hollow beads as well as admixture in the basis of the analysis to the influencing factors of its durability so as to can improve its sulfate resistance durability.
\end{abstract}

\section{Introduction}

In recent years, in order to consisent with our country 's the Twelfth Five-year Planning important topic-----architectural energy saving, and with the global sustainable development strategy, Vitreous beads insulation bearing concrete has got development and promotion. This material bases on the common concrete, mixes with a certain amount of mineral and vitrified beads thermal material instead of coarse and fine aggregate, which makes it has good thermal insulating properties and seismic performance, and its unit weight is lighter. It is a kind of construction materials which has broad prospects ${ }^{[1]}$.

Concrete has a complex component which has a very complex reaction with the harmful substance in the environment and then cause concrete performance degradation. Soil, underground water, sea water, rotten organic matter and industrial waste water containing sulfuric acid root ion, they can cause concrete expansion, craze, fall off ,make concrete degradation, which seriously influence the concrete durability and service life. At present, there are many studys on the concrete sulfate erosion performance, which has made many meaningful results. Although there are studys on resistance to sulfate erosion of vitrified beads insulation bearing concrete, because it is a new kind of meterials, the present study is not enough and lack of systematic. Therefore, no matter in the aspect of materials science progress or for the purpose of further application of the vitrified beads insulation bearing concrete, the studys on the vitreous beads insulation bearing concrete resistance of sulfate erosion performance have important significance. This paper starts from the influence factors, through theoretical analysis system in three aspects of glass beads of insulation material, admixture, water-cement ratio of its resistance to sulfate durability.

\section{Test basic information}

Test Material. Cement: select PO42.5 ordinary portland cement produced by Shanxi Jigang Port cement company

Stones: select Shanxi Qingxu gravel, particle size $5 \sim 12 \mathrm{~mm}$, the bulk density is $630 \mathrm{~kg} / \mathrm{m} 3$.

Sand: select Shanxi Jincheng medium sand, fineness modulus 1.6 2.2, bulk density $1500 \mathrm{~kg} / \mathrm{m} 3$.

Water: tap water.

Admixture: choose the new type of active admixture developed by Shanxi high-tech enterprise Taiyuan Sikeda Technology Development Co., Ltd.

Glass beads: select and use products of Sikeda Taiyuan Science and Technology Development Co., Ltd.

Test Method. In this paper, on the basis of "the long-term performance and durability test 
method of ordinary concrete" (standards GB/T50082-2009), use changes in compressive strength, which has a clear physical meaning, as the evaluation of the degree of erosion. For qualitatively evaluate the concrete within a relatively short time, the sulphate resistance test specimen molding size is $100 \mathrm{~mm} * 100 \mathrm{~mm} * 100 \mathrm{~mm}$, after the 28 days standard curing, one group soaked in sodium sulfate solution with concentration of $5 \%$ ( $\mathrm{PH}$ value is always maintained at about 7 ), the solution was replaced every two months. In order to eliminate the impact of temperature and humidity changes to the test, the test soak specimen seal erosion solution was placed in conditions of constant temperature $(20 \pm 2){ }^{\circ} \mathrm{C}$; another group was on the conservation of water with the same temperature. Till time reach $(15 \pm 0.5) \mathrm{h}$, get out of the specimen and dried them. When the temperature reached $80^{\circ} \mathrm{C}$ and maintain this temperature for $6 \mathrm{~h}$, then naturally cooled until the temperature reached $25^{\circ} \mathrm{C}$ $\sim 30^{\circ} \mathrm{C}$, maintain $2 \mathrm{~h}$. Repeat this till reach the specifications prescribed in the standard about the dry the wet cycles .Then timely test the compressive corrosion coefficient, i.e. the ratio of the compressive strength of test piece immersed in the erosion solution to that in the water with the same peer age ${ }^{[2]}$.

Test program design. Three kinds of water-cement ratio $0.5,0.525,0.55$; admixture dosage is $1.5 \%$ $1.9 \%, 2.3 \%$; glass beads dosage $0 \%, 130 \%{ }^{[3]}$. When prepared, keep the concrete mix is basically the same. Experiment ratio was shown in Table 1.

Table 1 Test proportion

\begin{tabular}{cccccc}
\hline $\begin{array}{c}\text { test num } \\
\text { ber }\end{array}$ & $\begin{array}{c}\text { water } \\
\text { cement } \\
\text { ratio }\end{array}$ & $\begin{array}{c}\text { cement } \\
\text { content }\left(\mathrm{kg} / \mathrm{m}^{3}\right)\end{array}$ & $\begin{array}{c}\text { sand } \\
\text { content }\left(\mathrm{kg} / \mathrm{m}^{3}\right)\end{array}$ & admixture(\%) & $\begin{array}{c}\text { glazed hollow } \\
\text { bead(\%) }\end{array}$ \\
\hline 1 & $1(0.5)$ & $3(405)$ & $2(650)$ & $2(1.9)$ & $1(0)$ \\
2 & $2(0.525)$ & $1(365)$ & $1(630)$ & $1(1.5)$ & $2(0)$ \\
3 & $3(0.55)$ & $2(385)$ & $3(670)$ & $3(2.3)$ & $3(130)$ \\
4 & $1(0.5)$ & $2(385)$ & $1(630)$ & $2(1.9)$ & $3(130)$ \\
5 & $2(0.525)$ & $3(405)$ & $3(670)$ & $1(1.5)$ & $1(0)$ \\
6 & $3(0.55)$ & $1(365)$ & $2(650)$ & $3(2.3)$ & $2(0)$ \\
7 & $1(0.5)$ & $1(365)$ & $3(670)$ & $1(1.5)$ & $3(130)$ \\
8 & $2(0.525)$ & $2(385)$ & $2(650)$ & $3(2.3)$ & $1(0)$ \\
9 & $3(0.55)$ & $3(405)$ & $1(630)$ & $2(1.9)$ & $2(0)$ \\
10 & $1(0.5)$ & $1(365)$ & $1(630)$ & $3(2.3)$ & $1(0)$ \\
11 & $2(0.525)$ & $2(385)$ & $3(670)$ & $2(1.9)$ & $2(0)$ \\
12 & $3(0.55)$ & $3(405)$ & $2(650)$ & $1(1.5)$ & $3(130)$ \\
13 & $1(0.5)$ & $3(405)$ & $3(670)$ & $3(2.3)$ & $2(0)$ \\
14 & $2(0.525)$ & $1(365)$ & $2(650)$ & $2(1.9)$ & $3(130)$ \\
15 & $3(0.55)$ & $2(385)$ & $1(630)$ & $1(1.5)$ & $1(0)$ \\
16 & $1(0.5)$ & $2(385)$ & $2(650)$ & $1(1.5)$ & $2(0)$ \\
17 & $2(0.525)$ & $3(405)$ & $1(630)$ & $3(2.3)$ & $3(0)$ \\
18 & $3(0.55)$ & $1(365)$ & $3(670)$ & $2(1.9)$ & $1(0)$ \\
\hline
\end{tabular}

\section{Experimental data and its processing}

Table 2 The compressive strength of the block in $\mathrm{Na}^{2} \mathrm{SO}_{4}$ solution

$$
\mathrm{Na}_{2} \mathrm{SO}_{4}
$$$$
\text { compression strength (MP) }
$$

$0 \mathrm{~d}$

$10 \mathrm{~d}$

$20 d$

$30 d$ 


\begin{tabular}{ccccccc}
\hline \multicolumn{2}{l}{ environment (g/L) } & \multicolumn{6}{l}{} \\
\hline \multirow{2}{*}{ ing } & rins & 0.467 & 0.472 & 0.483 & 0.485 & 0.488 \\
& & & & & & \\
& 4.5 & 0.453 & 0.459 & 0.473 & 0.494 & 0.465 \\
& 9 & 0.462 & 0.471 & 0.476 & 0.458 & 0.447 \\
& 18 & 0.465 & 0.457 & 0.478 & 0.507 & 0.402 \\
\hline
\end{tabular}

\section{Experiment results and discussion}

Effects of water cement ratio. Under the condition of not adding additive, corrosion resistance coefficients of concrete with different water-cement ratio vary with the changes of wetting and drying cycle times. The corrosion resistance coefficient of the concrete test specimen with the water-cement ratio of 0.5 began to decrease after a period time of 40 times wetting and drying cycles and for the ratio of 0.525 it began to decline after 10 times cycles. This demonstrates lowering water-cement ratio can relieve the corrosion of sulfate but it cannot solve the problem of sulfate resistance of concrete fundamentally.

In the preliminary stage of wetting and drying cycles, sulfate ions diffused and penetrated into the set cement then they experienced physical and chemical changes. Finally, crystallized products were created and voids were filled with them, which made the structure denser. However, products were not enough to give rise to expansion so the compressive strength in sulfate is higher than that in water. But with the continuous increase of cycle times, expansion products were generated and accumulated ceaselessly, resulting in the increasing of the stress and the appearance of the microcracks inside the concrete. At the moment, the concrete structure was damaged and the corrosion resistance coefficient began to fall. Under the condition of the same materials, with lower water-cement ratio, concrete can have higher density and good permeability resistance performance and it can help to stop the invasion of sulfate ions therefore the corrosion resistance performance of concrete can be promoted and the change of compressive corrosion resistance coefficient becomes smaller. So for the concrete with the demand of corrosion resistance, water-cement ratio must be controlled strictly ${ }^{[4]}$.

Effects of glazed hollow beads. The Vitrified beads particles is a kind of composite lightweight aggregate admixture which has a good grade. In the mixing process, the composite lightweight aggregate admixture can close-grained filling to the space between the other kinds of aggregate admixture. In addition, the combination of the additive agent and the vitrified beads makes the vitreous bead more closely to the stone, the sand and the cement particles ${ }^{[5]}$. That can effectively reduce concrete internal pore, and make the concrete denser. In this way, the probability that the external environment of sulfuric acid root ion intruding into concrete internal was reduced, and the probability of the generation of the ettringite, gypsum and the other expansion product will be reduced correspondingly. Therefore, the vitreous beads insulation materials have beneficial effects on the concrete sulfate attack resistance ability.

Fffects of admixture. At present, the additive we used is the high efficiency water reducing agent, which is the most commonly used admixture in engineering. The use of water reducing agent can greatly improve the fluidity of concrete when keeping the water cement ratio unchanged, or reduce water consumption when maintaining concrete liquidity unchanged ${ }^{[6]}$. In addition, water reducing agent also makes cement particle and the water affinity increase, the cement particle can fully be surrounded by water molecules, the water molecule can penetrate to the smaller channel. This is helpful to cement particle soaked, and make it more uniform dispersion in concrete batch, Concrete viscous and homogeneity are improved. In this way, it can effectively improve the concrete sulfate attack resistance ability.

\section{Summary}


For the vitrified beads insulation bearing concrete, reduce water cement ratio can effectively prevent intrusion of sulfuric acid root ion, improve its erosion performance. The water cement ratio should be strictly controlled for the concrete which have resistance to sulfate erosion requirements.

Compared with ordinary concrete, the vitreous beads insulation bearing concrete has better resistance to sulfate erosion ability.

Although high efficiency water reducing agent can improve concrete compactness by lowering water cement, it can only delay but not prevent the concrete sulfate and sulfuric acid erosion damage.

\section{References}

[1] Author: Zhu Li, Zeping Zhang, Yuanzhen Liu. The importance of energy in bulldings and introduction of a new technipue published by Engineer Mechanics.(2006).

[2] Long-term performance and durability of ordinary concrete test method standard publish by China Building Industry Press.(2009).

[3] Author: San xiang . Concrete sulphate corrosion resistance mechanism and its effect published by Heilongjiang communication science and technology.(2010).

[4] Author: Xiuhua Zheng.Study on resistance to sulfate attack of lightweight aggregate concrete as published by creat 2005 .

[5] Author: Wei Wang.Durability Experimental Research of Glazed Hollow Bead Concrete. Master degree thesis. Taiyuan University of Technology.2012.

[6] Author:Junqi Zhang. The Study on Durability of Thermal Insulation Glazed Hollow Bead Mortar under the Sulfate Attack. Taiyuan University of Technology.2012. 